\title{
Pankreatik endokrin tümörü taklit eden Intrapankreatik aksesuar dalak
}

\section{Intrapancreatic accessory spleen imitating a pancreatic endocrine tumour}

\author{
Mehmet Akif Türkoğlu*, Erdal Birol Bostancı, Melih Ereren, Seda Yamak, \\ Rıza Sarper Ökten, Musa Akoğlu
}

Genel Cerrahi Anabilim Dalı (Dr. M. A. Türkoğlu), Akdeniz Üniversitesi Tıp Fakültesi, TR-07059 Antalya, Gastroenterolojik Cerrahi Kliniği (Prof. Dr. E. B. Bostancı, Prof. Dr. M. Akoğlu), Radyoloji Kliniği (Dr. M. Ereren, Dr. R. S. Ökten), Patoloji Kliniği (Dr. S. Yamak), Türkiye Yüksek İhtisas Eğitim ve Araştırma Hastanesi, TR-06230 Ankara

\section{Özet}

Aksesuar dalak toplumun yaklaşı \%10'unda görülen ve embriyolojik gelişim sırasında oluşan bir anomalidir. Pankreasta lokalize olduğunda hipervasküler pankreatik tümörü taklit edebilir ve tanısal güçlüğe neden olabilir. Vakaların çoğu cerrahi rezeksiyondan sonra tanımlanır. Bu yazımızda nöroendokrin tümör şüphesiyle laparoskopik dalak koruyucu distal pankreatektomi yapılan 52 yaşındaki bir erkek olguyu sunuyoruz. Postoperatif histopatolojik inceleme ile lezyonun intrapankreatik aksesuar dalak olduğu açığa çıktı.

Anahtar sözcükler: Aksesuar dalak, nöroendokrin tümör, laparoskopi, distal pankreatektomi

\begin{abstract}
Accessory spleens are present in $10 \%$ of population and are formed during embryonic development. When an accessory spleen is located in the pancreas, it may mimic a hypervascular pancreatic tumor and can make a diagnostic difficulty. Most of the cases were identified only after surgical resection. Herein, we present the case of a 52-year old man whom laparoscopic spleenpreserving distal pancreatectomy was performed with suspicion of neuroendocrine tumor. Postoperative histopathological examination revealed the intrapancreatic accessory spleen.
\end{abstract}

Keywords: Accessory spleen, neuroendocrine tumour, laparoscopy, distal pancreatectomy

Geliş tarihi/Received: 22 Ağustos 2012; Kabul tarihi/Accepted: 12 Ekim 2012

*Iletişim adresi:

Dr. Mehmet Akif Türkoğlu, Genel Cerrahi Anabilim Dalı, Akdeniz Üniversitesi Tıp Fakültesi, TR-07059 Antalya. E-posta: macturko@ hotmail.com

\section{Giriş}

Aksesuar dalak genel toplumun yaklaşı \%10'unda görülen ve embriyolojik gelişim sırasında oluşan bir anomalidir. En sık yerleşim yeri splenik hilus olup sonraki en sık lokalizasyonu pankreas kuyruğudur. Otopsi serilerinde aksesuar dalak olgularının \%17'sini intrapankreatik lokalizasyon oluşturmaktadır [1]. Bu lokalizasyondaki olgular pankreatik tümöre benzediğinden tanı koymak güçtür. Biz burada pankreas nöroendokrin tümörüyle karışan intrapankreatik aksesuar dalak (IPAD) olgumuzu sunmayı amaçladık.

\section{Olgu sunumu}

Elli iki yaşındaki erkek olgumuz kabızlık ve ara ara oluşan karın ağrısı yakınmaları ile polikliniğimize basvurdu. Yapılan dinamik Bilgisayarlı Tomografi (BT)'de pankreas kuyruk kesimi parankiminde $22 \times 15 \mathrm{~mm}$ boyutlarında bir kitle saptandı. İntravenöz kontrast madde (IVKM) öncesi pankreas parankimine göre hafif hiperdens görünümde 
olan, IVKM sonrası kontrastlanan ve tüm fazlarda pankreas parankimine göre belirgin hiperdens olarak izlenen kitlenin pankreas nöroendokrin tümörü olabileceği düşünüldü (Resim 1). Alt ve üst gastrointestinal sistem endoskopileri ve Kromogranin A haricinde tümör belirteçleri (karsinoembriyojenik antijen, kanser antijen 19-9, alfa-fetoprotein) normal olan olguya tanı ve biyopsi amaçlı endosonografi yapıldı. Ancak kitleye, lokalizasyonu nedeniyle biyopsi yapılamadi. Kromogranin A düzeyi $270 \mathrm{mg} / \mathrm{mL}$ olan hastaya pankreas nöroendokrin tümörü şüphesiyle laparoskopik dalak koruyucu distal pankreatektomi yapıldı. Histopatolojik inceleme ile lezyona IPAD tanısı konuldu (Resim 2, 3). Olgu, sorunsuz olarak altıncı günde taburcu edildi.
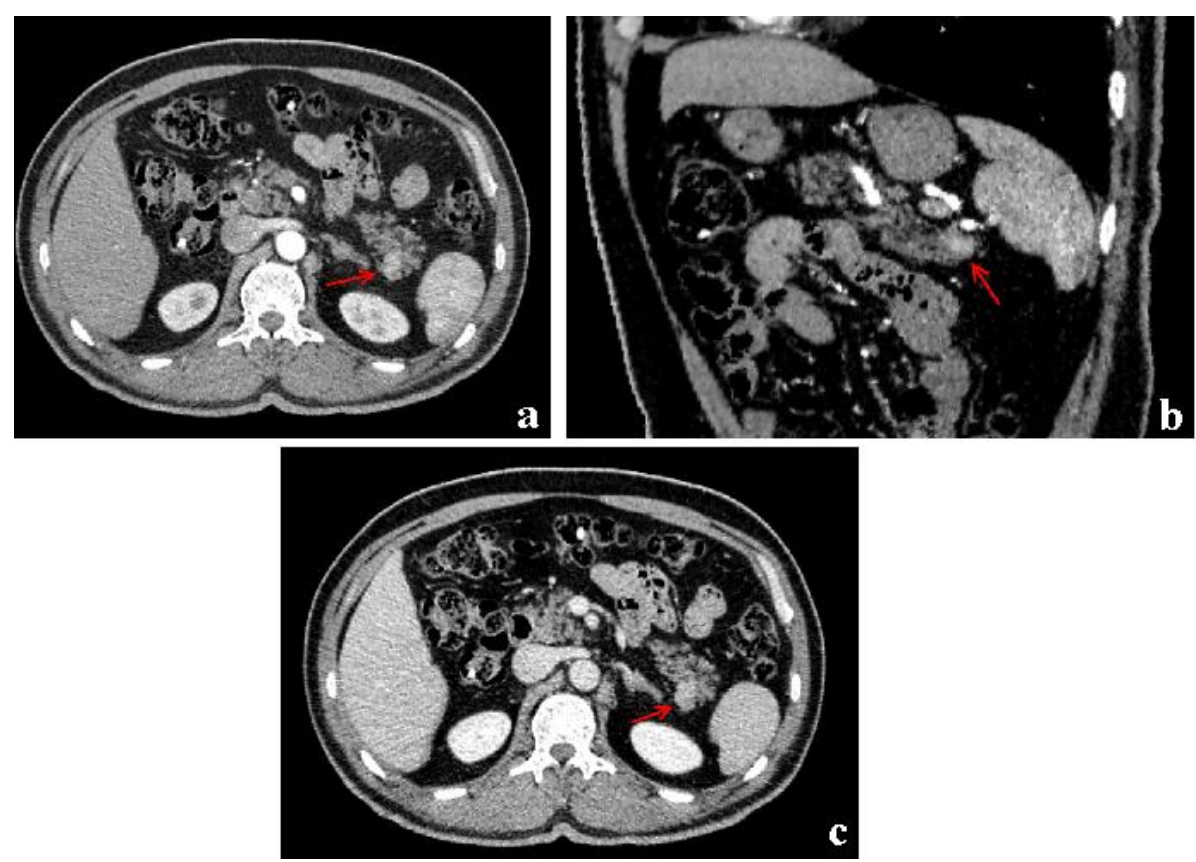

Resim 1a. Arteriyel fazda elde olunan aksiyel 1b. Oblik sagittal multiplanar reformat ve 1c. Venöz fazda elde olunan aksiyel, kontrastlı BT görüntülerinde; pankreas kuyruk kesiminde lokalize olan ve dalak parankimi ile benzer karekterde kontrastlanarak pankreas parankimine göre hiperdens görünümde olan kitle lezyonu.

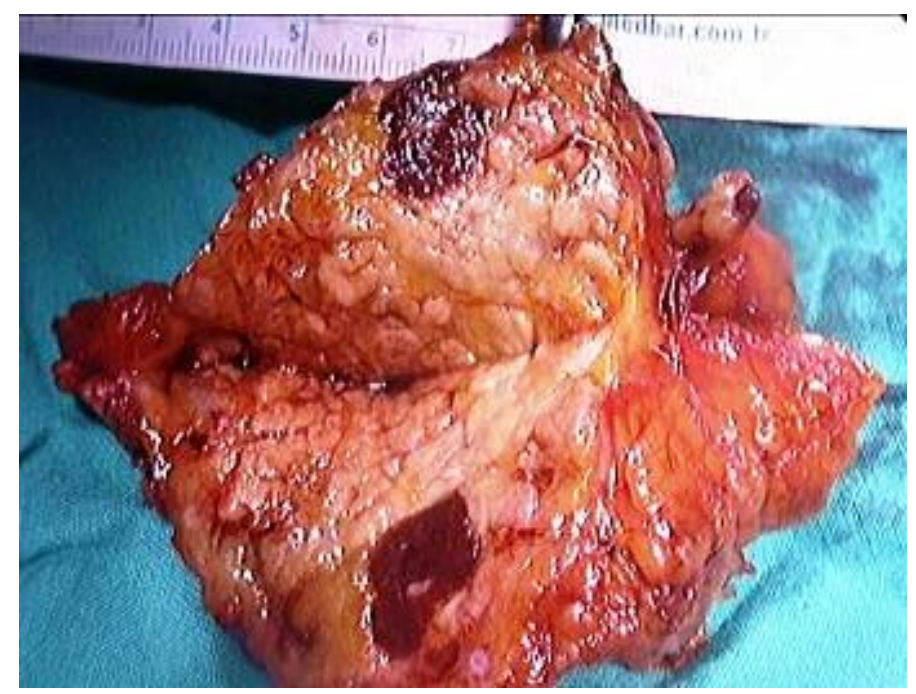

Resim 2. Rezeke edilen pankreas parankiminde sınırları belirgin kitle lezyonu. 


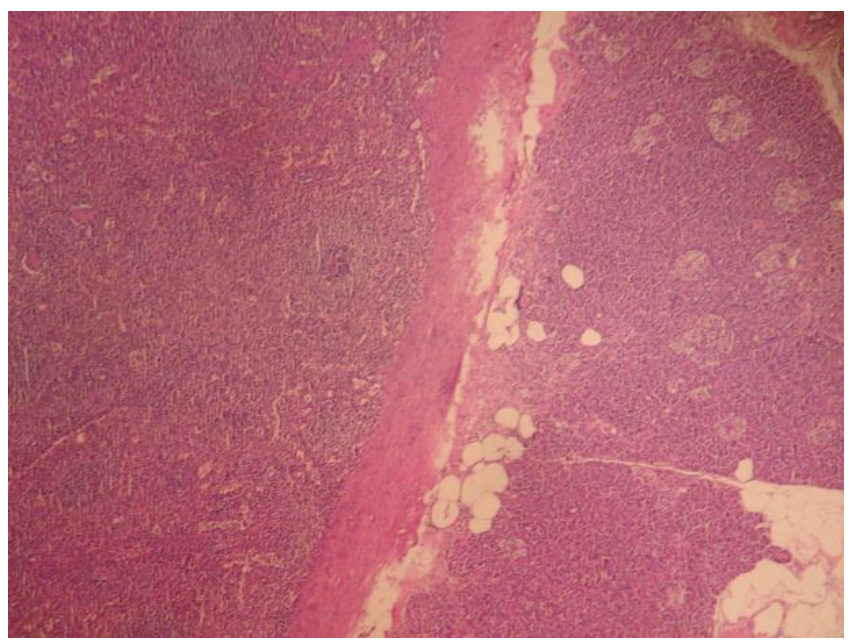

Resim 3. Histopatolojik görüntülerde pankreas dokusunda fibröz kapsül ile çevrili kırmızı ve beyaz pulpanın seçildiği ektopik dalak (H\&E).

\section{Tartışma}

Aksesuar dalak konjenital olarak splenik dokunun dalaktan ayrı heterotopik lokalizasyonda bulunmasıdır. Genellikle dorsal mezogastriumda lokalize, splenik prekürsör yapının yetersiz füzyonuna bağlı olarak gelişmektedir [2]. Üç bin olguluk bir otopsi serisinde \%12,1 oranında aksesuar dalak saptanmış, bunların da \%65'inin bir santimetre veya daha küçük olduğu belirlenmiştir [3]. Aksesuar dalak sıklıkla dalak hilusunda veya pankreas kuyruğuna yakın kısımda gözlenir. İAD, nadir gözlenen bir antite olup literatürde az sayıda olgu bildirilmiştir [4]. IPAD, izole asemptomatik anomali olarak gözlenmesine karşın bazen klinik önem arzetmektedir. Radyolojik olarak nadiren tanınır ve nöroendokrin tümör, pankreatik adenokarsinom, solit psödopapiller tümor, adenom ve metastazlar ile karışabilir [4-7]. Çoğunda, bizim olgumuzda olduğu gibi tanı, cerrahi rezeksiyon sonrası konulur $[4,5]$. IPAD genellikle yuvarlak şekilli, iyi sınırl, BT'de karakteristik olarak homojen kontrastanan lezyon görünümündedir ve genellikle 2 cm'den küçük boyuttadır [7]. Ancak İPAD' in BT, manyetik rezonans görüntüleme (MRG) ve ultrason bulguları nöroendokrin tümör ya da asiner hücreli karsinom gibi hipervasküler pankreas tümörleri ile oldukça benzer olduğundan görüntülemeye dayalı kesin tanı zor olabilir. Pankreas endokrin tümörlerinin \%30-40'1 non-fonksiyone olup hormon düzeylerinin normal olması bu tümörlerin benign olduğunu göstermez. Ayırıcı tanıda oktreotid sintigrafisinin kullanımı, dalak dokusu da somatostatin reseptörlerini eksprese edebildiğinden sınırlıdır [8]. İPAD tanısından şüphe durumunda en spesifik görüntüleme metodu Tc 99m sülfür kolloid ile yapılan nükleer sintigrafidir [9]. Ancak İPAD'ların çoğunun boyutlarının küçük olması ve sintigrafinin BT ve MR 'den daha düşük bir anatomik rezolüsyon sağlaması yanlış tanı konulmasına neden olabilir $[4,6]$. Ayırıcı tanıda bir diğer yöntem mikrogranüller kullanılarak yapılan kontrastlı ultrasonografidir. Geç fazda granüllerin yalnızca hepatosplenik parankim tarafindan tutulması aksesuar dalak ile pankreas tümörünü ayırmaya yardımcıdır [10]. Yine endoskopik ultrason eşliğinde ince iğne aspirasyon biyopsisi duyarlı bir testtir ancak lezyonun yerleşimi itibariyle işlem zor olabilir [11]. Laparoskopik distal pankreatektomi, nöroendokrin tümörler, kistik neoplazi ve bazı inflamatuar hastalıklarda tercih edilmektedir. Splenektominin kombine diğer major abdominal organlarla rezeksiyonu, özellikle enfektif komplikasyonlar olmak üzere postoperatif morbiditede artış ile birliktedir. Laparoskopik dalak koruyucu pankreatektomide hem açı cerrahiye hem de laparoskopik spleno-pankreatektomiye göre daha az intraoperatif kan kaybı, daha az postoperatif pankreatik fistül, daha kısa hastanede yatış zamanı ve daha iyi hayat kalitesi gözlenmiştir [12-14]. Yine dalak koruyucu cerrahi uzun dönemde kapsüllü bakterilere bağlı postsplenektomi sepsisini önlemektedir [12]. 
Asemptomatik intrapankreatik bir kitle saptandığında, dinamik kontrastlı BT incelemesinde tüm fazlarda kitlenin dalak parankimi ile aynı derecede kontrastlanması aksesuar dalak tanısını düşündürmelidir. Ancak birçok tanı aracı olmasına rağmen pankreas tümörüyle ayırıcı tanı zordur. Ayırıcı tanısı şüpheli bu tür olgulara laparoskopik yaklaşım ile postoperatif dönemde avantaj sağlanmaktadır.

\section{Kaynaklar}

1. Zeman M, Zembala-Nożyńska E, Sczasny J, Strączyński M, Wideł M. Intrapancreatic accessory spleen imitating a pancreatic neoplasm. Pol Przegl Chir 2011; 83: 568-70.

2. Chin S, Isomoto H, Mizuta Y, Wen CY, Shikuwa S, Kohno S.Enlarged accessory spleen presenting stomach submucosal tumor. World J Gastroenterol 2007; 13: 1752-4.

3. Halpert B, Gyorkey F. Lesions observed in accessory spleens of 311 patients. Am J Clin Pathol 1959; 32: 165-8.

4. Sothilingam N, Leedahl T, Kriegler S, Kanthan R, Moser MA. Intrapancreatic accessory spleen: A case report and review of the literature. Int J Surg Case Rep 2011; 2: 128-30.

5. Touré L, Bédard J, Sawan B, Mosimann F. Case note: intrapancreatic accessory spleen mimicking a pancreatic endocrine tumour. Can J Surg 2010; 53: E1-2.

6. Guo W, Han W, Liu J, Jin L, Li JS, Zhang ZT, Wang Y. Intrapancreatic accessory spleen: a case report and review of the literature. World J Gastroenterol 2009; 15: 1141-3.

7. Kurmann A, Michel JM, Stauffer E, Egger B. Intrapancreatic Accessory Spleen Misdiagnosed as a Nonsecreting Endocrine Tumor: Case Report and Review of the Literature. Case Rep Gastroenterol 2010; 4: 210-4.

8. Brasca LE, Zanello A, De Gaspari A, De Cobelli F, Zerbi A, Fazio F, Del Maschio A. Intrapancreatic accessory spleen mimicking a neuroendocrine tumor: magnetic resonance findings and possible diagnostic role of different nuclear medicine tests. Eur Radiol 2004; 14: 1322-3.

9. Sica GT, Reed MF. Case 27: intrapancreatic accessory spleen. Radiology 2000; 217: 134-7.

10. Ota $\mathrm{T}$, Ono $\mathrm{S}$. Intrapancreatic accessory spleen: diagnosis using contrast enhanced ultrasound. Br J Radiol 2004; 77: 148-9.

11. Lin J, Jing X. Fine-needle aspiration of intrapancreatic accessory spleen, mimic of pancreatic neoplasms. Arch Pathol Lab Med 2010; 134: 1474-8.

12. Warshaw AL. Distal pancreatectomy with preservation of the spleen. J Hepatobiliary Pancreat Sci 2010; 17: 808-12.

13. Venkat R, Edil BH, Schulick RD, Lidor AO, Makary MA, Wolfgang CL. Laparoscopic distal pancreatectomy is associated with significantly less overall morbidity compared to the open technique: a systematic review and metaanalysis. Ann Surg 2012; 255: 1048-59.

14. Choi SH, Seo MA, Hwang HK, Kang CM, Lee WJ. Is it worthwhile to preserve adult spleen in laparoscopic distal pancreatectomy? Perioperative and patientreported outcome analysis. Surg Endosc 2012 (DOI: 10.1007/s00464-012-2306$4)$. 